AperTO - Archivio Istituzionale Open Access dell'Università di Torino

\title{
Management of Chronic Diarrhea in an Adult Horse
}

\section{This is the author's manuscript}

Original Citation:

Availability:

This version is available http://hdl.handle.net/2318/131714

since 2017-07-27T14:29:00Z

Published version:

DOI:10.1016/j.jevs.2012.05.061

Terms of use:

Open Access

Anyone can freely access the full text of works made available as "Open Access". Works made available under a Creative Commons license can be used according to the terms and conditions of said license. Use of all other works requires consent of the right holder (author or publisher) if not exempted from copyright protection by the applicable law. 


\section{(5) \\ UNIVERSITÀ DEGLI STUDI DI TORINO}

This Accepted Author Manuscript (AAM) is copyrighted and published by Elsevier. It is posted here by agreement between Elsevier and the University of Turin. Changes resulting from the publishing process - such as editing, corrections, structural formatting, and other quality control mechanisms - may not be reflected in this version of the text. The definitive version of the text was subsequently published in

Management of chronic diarrhea in an adult horse. Journal of Equine Veterinary Science Volume 33, Issue 2, February 2013, Pages 130-135 http://dx.doi.org/10.1016/j.jevs.2012.05.061

You may download, copy and otherwise use the AAM for non-commercial purposes provided that your license is limited by the following restrictions:

(1) You may use this AAM for non-commercial purposes only under the terms of the CC-BY-NCND license.

(2) The integrity of the work and identification of the author, copyright owner, and publisher must be preserved in any copy.

(3) You must attribute this AAM in the following format: Creative Commons BY-NC-ND license (http://creativecommons.org/licenses/by-nc-nd/4.0/deed.en), [+ Digital Object Identifier link to the published journal article on Elsevier's ScienceDirect ${ }^{\circledR}$ platform $]$ 
Management of chronic diarrhea in an adult horse

Valle Emanuela DVM, $\mathrm{PhD}^{\mathrm{a}}$, Gandini Marco DVM PhD ${ }^{\mathrm{b}}$, Domenico Bergero DVM ${ }^{\mathrm{a}}$

${ }^{a}$ Department of Animal Production, Epidemiology and Ecology, Faculty of Veterinary Medicine, Torino, Italy.

${ }^{\mathrm{b}}$ Department of Animal Pathology, Faculty of Veterinary Medicine, Torino, Italy

* Corresponding author. E-mail: emanuela.valle@unito.it Address: Dipartimento di Produzioni Animali, Epidemiologia ed Ecologia, Facoltà di Medicina Veterinaria di Torino, Via L. Da Vinci 44, 10095 Grugliasco (TO), Italy. Telephone: +390116709207 Fax: +390116709240 
Chronic diarrhea could be a challenge from both the diagnostic and therapeutic point of view. This case report will discuss the clinical approach to the evaluation of chronic diarrhea with the production of free fecal water in an adult horse. The discussion of this case report may provide further information and describe a possible therapeutic option with sulfasalzine, focusing on the nutritional management of chronic diarrhea in adult horses. Nutritional management could be of higher importance for horses that suffer from this problem because it improves the well-being of the hindgut environment. In the present case report, motility abnormalities were identified without other physiological disturbances of colonic function or a decrease in body weight, and the priority was the following: (1) rebalancing of the diet to the real nutritional requirements of the patient, (2) avoiding excess carbohydrate from both forage and concentrate, (3) selecting the right proportion between good quality first-cut meadow hay and grounded and pelleted meadow hay that helps to reduce mechanical and physical load of the colon and could help in the formation of more homogeneous digesta, (4) reducing the stress with adequate feed consumption time, meal size, and time spent in a overgrazed paddock, and (5) increasing the proportion of omega-3 fatty acids in the diet. With the nutritional plan and management and the initial use of sulfasalazine, the horse maintained a good quality of the feces with a reduced or absent production of the free fecal water.

Keywords Horse; Chronic diarrhea; Fecal water; Nutrition; Sulfasalazine; Pellet diet

\section{Introduction}

Diarrhea that persists for weeks or months is a frustrating problem from the diagnostic and therapeutic point of view, both for the owner and the clinicians. In this condition, feces are soft and watery, and the amount excreted is greater than normal [1]. Horses not only have the production of watery feces, but also can have "free fecal water" where horses could even produce normal feces; however, before, after, or during, or independent from defecation, fecal water is produced and pollutes the tail and legs, and may even cause skin lesions [2]. Diarrhea, to be considered 'chronic', has to have been present for at least 7 to 14 days [3]. In some cases, the diarrhea will persist for weeks or months, with recurrent attacks of changed feces texture from "cowpat" consistency to real watery diarrhea, separated by periods of relatively normal fecal consistency. In the adult horse, chronic diarrhea is almost invariably associated with large intestinal (cecal and colonic) disease. It could be caused either by physical damage to the colonic wall or physiological disturbances of colonic function [3]. The causes of chronic diarrhea could be different, and in general could be due to inflammatory causes or imbalance of the normal physiological processes. Among inflammatory causes, different etiologies could be involved such as infection (bacterial or parasitic) and 
infiltrative disorder with involvement of the hindgut (alimentary lymphosarcoma, multisystemic eosynophylic epitheliotropic disease, proliferative enteropathy, and granulomatous enteritis); other causes of inflammation could be related to the ingestion of sand or the use of nonsteroidal antiinflammatory drugs (NSAIDs) [4] and [5]. Noninflammatory causes could be related to alteration of the fermentation of the microorganism in the hindgut or extraintestinal causes like heart failure, liver disease [5], motility abnormalities, or other physiological disturbances of colonic function that lead to an idiopathic dysfunction of the hindgut.

However, many of the causes and mechanisms of chronic diarrhea are poorly understood, and horses affected by chronic diarrhea are often diagnostic and therapeutic challenges. A definitive diagnosis of the cause of chronic diarrhea will be achieved in only $60-70 \%$ of cases, and in many of these, it will only become apparent at postmortem examination [3].

The aim of this case report is to describe the clinical approach to the evaluation of chronic diarrhea in an adult horse and the treatment proposed for the problem using a nutritional point of view.

\section{Case Description}

\subsection{Signalment and History}

A 12-year-old Württemberg warmblood horse, used for leisure eventing competitions, was evaluated for a history of chronic diarrhea and persistent free fecal water. A precise history record was available for the previous years. Since the time of purchase at age of 8 years, the horse had soft ("cowpat consistency") or watery feces with the production of free fecal water also independent from defecation. Initially, the owners related these episodes to "stressful" events such as changes in the management of the barn where the horse was stabled. According to the owner, the horse always had a normal appetite, good demeanor (calm and quiet), and a good body condition. The horse's vaccination history was adequate. Anthelmintics were routinely administered in a proper manner, and a fecal parasite examination was performed at least once a year.

The horse always manifested the problem in a cyclic way: first, the owner recorded an increase of free fecal water; this was followed by an increase of defecation episodes (5-6 times in an hour); and after a few days, watery feces or diarrhea was observed. Different feeds were tested by the owner, but no constant improvement was seen. The problem was always present; however, the owner reported an increase of the fecal water and the worsening of consistency of the feces when the batch of forage, usually consisting of first-cut meadow hay, was replaced with the first-cut hay mainly composed of ryegrass (Lolium multiflorum Lam. ssp. italicum).

No improvement was also obtained using prebiotics like fructo-oligosaccharides or inulin and probiotics like Lactobacillus spp. However, the use of fresh baker's yeast, Saccharomyces cerevisiae, 
at a dosage of $100 \mathrm{~g} / \mathrm{d}$ was reported to be beneficial because the feces returned to normal consistency even if the fecal water was still reasonably present. Treatment with NSAIDs for a lameness problem (phenylbutazone $2.2 \mathrm{mg} / \mathrm{kg}$ intravenously once a day for 3 days) was administered in the spring of the same year, but no association was recorded with the aggravation of the problem. A change in management routine (related to a new barn manager and a new routine) aggravated the situation, and the horse was brought for examination.

\subsection{Feeding Plan}

At the time of the visit, samples were taken to perform feed analysis. The horse was fed with $9 \mathrm{~kg}$ of first-cut meadow hay of medium quality $(6.5 \%$ crude protein $[\mathrm{CP}], 0.1 \%$ crude fat $[\mathrm{CF}], 33 \%$ crude fiber $[\mathrm{CFb}$ ], and $6.7 \%$ ash as fed basis), $1.5 \mathrm{~kg}$ of cereal-based concentrate $(12.4 \% \mathrm{CP}, 3.5 \%$ $\mathrm{CF}, 9.1 \% \mathrm{CFb}$, and $8.4 \%$ ash as fed basis), $1.5 \mathrm{~kg}$ of alfalfa and oat straw chaff $(12.8 \% \mathrm{CP}, 32 \%$ $\mathrm{CFb}$, and $11 \%$ ash as fed basis), and $120 \mathrm{~g}$ of soya oil. The ration was provided in four meals. No ryegrass hay was available at the time of the first visit.

\subsection{Physical Examination}

At physical examination, the horse had a BCS of 7 on a nine-point scale and a body weight of 620 $\mathrm{kg}$; its coat was in good condition. All the organs functioned normally, with no sign of dehydration, normal capillary refill time, and normal rectal temperature.

The horse continuously presented "cowpat" consistency feces alternated with watery diarrhea and free fecal water with or independent from defecation. This was confirmed by the presence of dirty bedding and walls and wet tail and hind limbs. The frequency of defecation was increased up to 5 to 6 times in an hour. During the production of free fecal water, the horse presented repeated tail swishing (tail movement to the left or the right) and alternate rhythmic movement of the hind limbs. Colic was never manifested, but the horse seemed to be a little apathetic and had some difficulties to be collected during flat work. No signs of surgery were present on the abdomen.

Examination of the digestive system showed normal appetite, normal oral cavity, dentition, and mastication; auscultation revealed an abdominal motility that was increased in the left upper and lower quadrant, but normal on the right abdomen.

\subsection{Diagnostic Procedure}


Differential diagnosis, common causes of chronic diarrhea, and procedure considered in the present case report are reported in Figure 1. Abdominal radiography was not considered because of the size of the horse. Rectal biopsy or exploratory laparotomy was refused by the owner because of the risks involved. The owner did not agree for liver biopsy because of the risks involved and the lack of biochemical indications for liver problem. A sugar absorption test was attempted but abandoned because of the horse's temperament. Fecal examination excluded infective causes or sand ingestion and also was performed to evaluate the visual pattern of the feces and $\mathrm{pH}$. The $\mathrm{pH}$ was determined immediately after defecation by mixing equal amounts of feces and double-deionized water and submerging the $\mathrm{pH}$ paper. The mean value obtained from three different samples was 6.4.

Hematological and biochemical parameters performed at the time of the visit (December 2009) are reported in Table 1. The analysis of the previous 3 years is also given. All hematological and biochemical parameters were within normal reference ranges.

\section{Pharmacological Treatment}

As all the diagnostic procedures gave negative results, and based on personal experiences, a tentative treatment with sulfasalazine (Salazopyrin EN, tablets; Pfizer, PHARMACIA Italia S.p.A., Milano) was initiated. This drug is a colon-specific prodrug commonly used for the treatment of inflammatory bowel diseases such as ulcerative colitis and Crohn disease in humans, as well in veterinary medicine (eg, eosinophilic colitis in dogs or cats and typhlocolitis in horses) [7]. Its mode of action is not well understood. The anti-inflammatory effect of the drug is probably because of inhibition of eicosanoid metabolism, and the interaction of 5-ASA with oxygen-derived free radicals is considered to be an essential mechanism of its effect [7]. The dosage was adapted based on the values commonly used in small animal practice $(16 \mathrm{mg} / \mathrm{kg}$ PO once a day for 5 days, followed by $8 \mathrm{mg} / \mathrm{kg}$ PO once a day for 10 days) [8]. The horse responded well to the sulfasalazine treatment. The diarrheal episodes subsided, and the quality of the feces improved, reaching good consistency with the absence of the fecal water in a few days. The treatment was subsequently suspended because of the concern of the owner about possible side effects (keratoconjuntivitis sicca). However, during the course of the treatment, there were no apparent side effects.

\section{Feeding Plan and Management}

Along with the sulfasalazine treatment, a dietary and management change was initiated. Nutritional requirements of the horse were calculated [9] according to that of an adult horse undergoing light exercise. The nutritional plan was formulated using $5 \mathrm{~kg}$ of good quality first-cut meadow hay (long stem; $7.5 \% \mathrm{CP}, 0.1 \% \mathrm{CF}, 29 \% \mathrm{CFb}$, and $6.2 \%$ ash as fed basis) provided in a small hole hay net, 5 
$\mathrm{kg}$ of grounded and pelleted meadow hay (Table 2), $1 \mathrm{~kg}$ of cereal-based concentrate (as described earlier), $120 \mathrm{~g}$ of soya oil, and $20 \mathrm{~g}$ of linseed oil and vitamin/mineral balancer. The feed was divided into six meals per day every 3 to 4 hours. The composition of the whole diet is reported in Table 3. The horse was also allowed access to an overgrazed paddock, limiting all possible kinds of stresses. An increase in daily exercise was also scheduled when there was an improvement seen in the fecal quality.

\section{Follow-up}

The horse responded well to the sulfasalazine treatment. The diarrheal episode subsided and the quality of the feces improved, reaching good consistency with the absence of the fecal water in a few days. The treatment after 15 days was subsequently suspended because of the concern of the owner about possible side effects like keratoconjuntivitis sicca [10]. Other side effects like agranulocytosis and thrombocytopenia were not investigated because the horse was in good condition and the treatment was of short duration.

With the nutritional plan and management, the horse maintained a good quality of feces and a reduced or absent production of the free fecal water. After 8 months a progressive increase of long stem meadow hay with the reduction of the ground and pellet meadow hay proportion (less than 3 $\mathrm{kg}$ ) was proposed to facilitate the daily management of the horse by the grooms. However, this caused a progressive worsening of the quality of the feces that assumed a "cowpat" consistency with the increase of the production of fecal water. A safe upper limit of $4 \mathrm{~kg}$ of ground and pellet meadow hay was optimal to maintain feces in an acceptable consistency and without any production of fecal water.

After 2 years, the horse presented again with "cowpat" consistency feces and free fecal water, with repeated tail swishing and other signs of discomfort during defecation. However, no watery feces were presented for more than 1 day. This worsening of the problem was associated with an abrupt change in the forage using Italian ryegrass hay (analysis revealed $7.7 \% \mathrm{CP}, 30 \% \mathrm{CFb}, 0.2 \% \mathrm{CF}$, and $7.8 \%$ ash) with the presence foreign materials (leaves from three branches and Rumex acetosa plants). Another treatment with sulfasalazine was started as described before, accompanied by a more strict control of hay quality. The horse responded immediately to the drug treatment and was then maintained with the prescribed diet management.

\section{Discussion}

A definitive diagnosis of the cause of chronic diarrhea was not possible, and an inflammatory colitis was suspected, reinforced by the response to the sulfasalazine tentative treatment. Chronic diarrhea 
could be a frustrating disease because the diagnosis could be difficult, and all the diagnostic procedures could give negative results. For this reason, it is important to focus also on the dietary management of the problem. Nutrition is an aspect of clinical therapy that is often overlooked, and dietary interventions are often based on anecdotal reports; however, it could not be ignored, especially in horses with the chronic disease. As the literature on the nutritional management is scarce, it is important that the dietary intervention is based on the clinical aspects of the problem.

Chronic diarrhea could be a combination of different mechanisms including mucosal inflammation and damage, impaired digestion, increased secretion across the gastrointestinal wall, and osmotic overload of the luminal contents [11].

As first, it is necessary to formulate a diet that takes into consideration the real nutritional requirement of the patient, as in the present case report, the horse was obviously overfed, having a BCS of 7. It also important to take into account the feed composition and quality, as diet characteristics are known to influence the well-being of the hind gut.

Diet characteristics were shown to influence both the cecal and colonic environments that could be influenced both by the forage and concentrate type. For example, the hindgut environment has a high sensitivity to high-starch diets [12]. According to Kronfeld and Harris [13], no more than $2 \mathrm{~g}$ of starch $/ \mathrm{kg}$ (ie $0.2 \%$ starch or about $1.4 \mathrm{~kg}$ of grain per meal) should be fed to avoid the risk of "dysbiosis" in the hindgut; however, when it is in excess and escapes amylase digestion, it is rapidly fermented to lactic acid, which has a $\mathrm{pK}$ of 3.8 , that is poorly absorbed and accumulates in the lumen. Lactate attracts water, setting the stage for osmotic diarrhea. Moreover, high-starch feeding represents a well-known risk factor for the development of gastrointestinal disorders, like lesions on the mucosal surface of the stomach and large intestine, and microecological dysfunction with colic [14]. For this reason, a diet with high content of starch should be avoided. In the present case, the given quantities of cereal-based concentrate were minimal. This was because of barn management practice (concentrate meal given to the other horses) and because small quantities of starch could be beneficial for the activity of microorganism in the hindgut. According to Peiretti and coworkers [15], cereals submitted to technological treatment and added to the first-cut meadow hay improve the horse's digestibility of the ration.

Diarrhea could be also because of colonic maldigestion that could be, in part, responsible for excess fecal water [16]. For this reason, it is important to focus the attention on the activity of the hindgut. The fermentation process, which takes place in this organ, is important not only for the energy requirement of the animals but also because short-chain fatty acids (SCFA) are particularly relevant for the hindgut mucosa health. With the absorption of SCFA, there is a net absorption of $\mathrm{NaCl}$, and this in turn is a major determinant of water absorption [17]. Moreover, among SCFA, butyrate has a 
prominent role at the colon level because it is the primary fuel for the colonocytes and its oxidation is involved in various important metabolic processes. It is important for the energy load to colonocytes, the enhancement of sodium and water absorption, and the synthesis of mucus and cell membranes in addition to its anti-inflammatory effect [18]. Good quality hay is necessary to promote the activity of the microorganism in the hindgut. Structural carbohydrates (chemically defined as neutral detergent fiber $[\mathrm{NDF}]$ ) are fermented to varying degrees by large intestinal microorganisms. NDF can be further partitioned into acid detergent fiber and hemicelluloses components. Fermentability of hemicelluloses and cellulose components of NDF is proportional to the amount of lignin in the cell wall (ADL). Higher lignin content results in lower total digestibility. Resistant compounds that are components of acid detergent fiber are not digested to any degree. Plant lignin content is determined by species and maturity and is influenced by environmental conditions [19].

To the author's knowledge, there are no reports available on the association of fecal water or "cowpat" consistency feces with the ingestion of Italian ryegrass. Even if the horse in this case presented with the problem while eating the typical regional first-cut meadow hay, the owner reported an increase in fecal water and the worsening of consistency of the feces generally when ryegrass hay was used. This is unlikely to be caused by immune-mediated intolerance, but could be related to an abrupt change from one batch of hay to another that might alter colon digesta and fecal consistency. This could be exacerbated by using forage rich in fructane such as Lolium multiflorum Lam. ssp. italicum that accumulates fructan as the main storage carbohydrate [20]. When fructan are given in excess, fermentations primarily in the cecum and large intestine occurs, resulting in the production of lactic acid and other toxins and amines [21] increasing inflammation and damage to the mucosa, causing malabsorption, increased secretion across the gastrointestinal wall, and osmotic overload of the luminal contents for the presence of lactate.

Large-volume fiber sources should be eliminated to reduce the mechanical and physical load on the compromised colon, to favor mucosal healing [22]. The greater bulk consumption of long hay increases the rate of passage, especially particulate digesta, through the hindgut, compared with pelleted diets of much smaller particle size. Chemical modification of the cell wall can lead to differences in physical properties of fiber modifying the water-binding capacity. Feeding of pelleted diets not only reduced passage rate but also led to a similar passage rate of particles and solutes [23]. Pelleted foods help to reduce the bulk feed and guarantee the mechanical rest. However, reducing particle size should not be confused with reducing fiber length [23]. In our opinion, it is better to select a pellet composed of meadow hay where the fiber is grounded or thinly crushed rather than 
chopped. The smaller the particles are, lower is the free water fraction and more homogeneous is the digesta, and the fiber is retained longer in the large colon [23] and [24].

Moreover, in our opinion, it is necessary to avoid complete pellet ration, which decreases the feeding consumption time, thus promoting gut acidosis. Gastrointestinal secretion may be constant rather than meal-induced [25]. It is important to select the correct proportion between pellet and long hay that could be assessed as a function of the fecal consistency, the meal schedule, and the feed consumption time. In this case report, a proportion of 50:50 between long stem hay (provided in small hole hay net) and pellet was considered as optimal.

The addition of soya oil and linseed oil increased the quantity of omega-3 fatty acids in the diet. In other species, the use of these substances decreases the production of cytokines involved with chronic inflammatory diseases. Circulating fatty acids can be influenced through targeted supplementation of these substances also in horses, even if the implications of increased n-3 plasma and tissue concentrations on specific physiological function in the equine remain to be elucidated [26].

\section{Conclusions}

Chronic diarrhea could be a challenge from both the diagnostic and therapeutic point of view. Tentative treatment with sulfasalzine $(10-20 \mathrm{mg} / \mathrm{kg}$ PO once a day) could be considered when a definitive cause is not proven. Care must be taken for possible collateral effects reported in other species such as dogs and cats, which nevertheless were not shown in this patient. Nutritional management could be of higher importance because it improves the well-being of the hindgut environment. In the case of chronic diarrhea, especially those caused by motility abnormalities without other physiological disturbances of colonic function with no decrease in body weight, it is necessary to consider the following: (1) rebalancing of the diet to the real nutritional requirements of the patient, (2) avoiding excess carbohydrate from both forage and concentrate, (3) selecting the right proportion between good quality first-cut meadow hay and grounded and pelleted meadow hay that helps to reduce the mechanical and physical load of the colon and could help in the formation of more homogeneous digesta, (4) reducing the stress with adequate feed consumption time, meal size, and time spent in a overgrazed paddock, and (5) increasing the proportion of omega-3 fatty acids in the diet. Taken together, these factors help to reduce the inflammation and influence the motility pattern, absorption, and secretion of nutrients in the colon.

Acknowledgments

The authors thank Dr. Lidia Sterpone for her analysis. 
Table 1 Hematological and biochemical parameters performed at the moment of the visit (last column) and during some of the previous recurrent attacks of chronic diarrhea and free fecal water.

\begin{tabular}{lllll}
\hline & February & January & January & December \\
& 2007 & 2008 & 2009 & 2009 \\
\hline HCT \% & 32.3 & 37.9 & 29 & 33 \\
HB g/dl & 11.9 & 11.9 & 10.6 & 12.3 \\
RBC & 7.0 & 7.4 & 5.9 & 7.0 \\
WBC x10/L & 7.9 & 5.7 & 7.46 & 8.7 \\
Neu \% & 63 & 55 & 61 & 56 \\
Alb g/dl & 2.9 & & 3.4 & 3.8 \\
ALP U/L & 112 & 122 & 119 & \\
ALT U/L & 13 & 52 & 4 & \\
AST U/L & 292 & 305 & 202 & 335 \\
BUN mg/dl & 14 & & & \\
CREA mg/dl & 1.4 & 1.4 & 1.5 & \\
GGT U/L & 55 & 13.7 & & 32 \\
Glu mg/dl & 94 & 87 & & \\
Bil Tot mg/dl & 1.8 & 1.31 & 2.13 & \\
TP mg/dl & 6.4 & 6 & 5.6 & \\
Glob g/dl & 3.5 & & & \\
CK & & & & \\
UREA mg/dl & & & & \\
LDH U/L & & & & \\
\hline
\end{tabular}

HCT, Hematocrit; HB, Hemoglobin; RBC, Red Blood Cells, WBC, White Blood Cells; Neu, Neutrophil; Alb, Albumin; ALP,Alkaline phosphatase; ALT, alanine aminotransferase; AST, Aspartate transaminase; BUN: blood urea nitrogen; CREA: Creatinine; GG: gamma-glutamyl transferase; GLU, Glucose; Bil Tot, Total bilirubine; TP, total protein; Glob, Globulin; CK, creatinkinase; LDH, Lactate dehydrogenase; 
Table 2 Chemical analysis and size dimension of the particles of the grounded and pelleted meadow hay used for the diet (medium values obtained from 6 samples using sieves with different mesh openings)

\begin{tabular}{llll}
\hline \multicolumn{2}{l}{ Analysis on the dry matter basis } & Size of the particles & $\%$ \\
\hline & $\%$ & $0-100 \mu \mathrm{m}$ & 21.9 \\
$\mathrm{PG}$ & 8.5 & $100-500 \mu \mathrm{m}$ & 36.2 \\
$\mathrm{CFb}$ & 25.5 & $500-1000 \mu \mathrm{m}$ & 17.5 \\
$\mathrm{Ash}$ & 9.5 & $1000-2000 \mu \mathrm{m}$ & 18.3 \\
$\mathrm{CF}$ & 2.5 & $2000-5000 \mu \mathrm{m}$ & 5.7 \\
& & $>5000 \mu \mathrm{m}$ & 0.4
\end{tabular}

$\mathrm{CP}$, crude protein; $\mathrm{CFb}$, Crude fiber; $\mathrm{CF}$, Crude fat

Table 3 Composition of the whole diet formulated for the chronic diarrhea

\begin{tabular}{ll}
\hline Analysis on the dry matter & \\
\hline Energy Mcal/Kg & 1.53 \\
$\mathrm{PG} \%$ & 9.80 \\
$\mathrm{CFb} \%$ & 31.50 \\
$\mathrm{Ash} \%$ & 9.23 \\
$\mathrm{CF} \%$ & 2.56 \\
DM intake \% of BW & 1.7 \\
\hline
\end{tabular}

Energy, estimated net energy content of the diet according to the French system (Martin Rosset, 1990); CP, crude protein; CFb; Crude fiber; CF: Crude fat; BW= body weight 


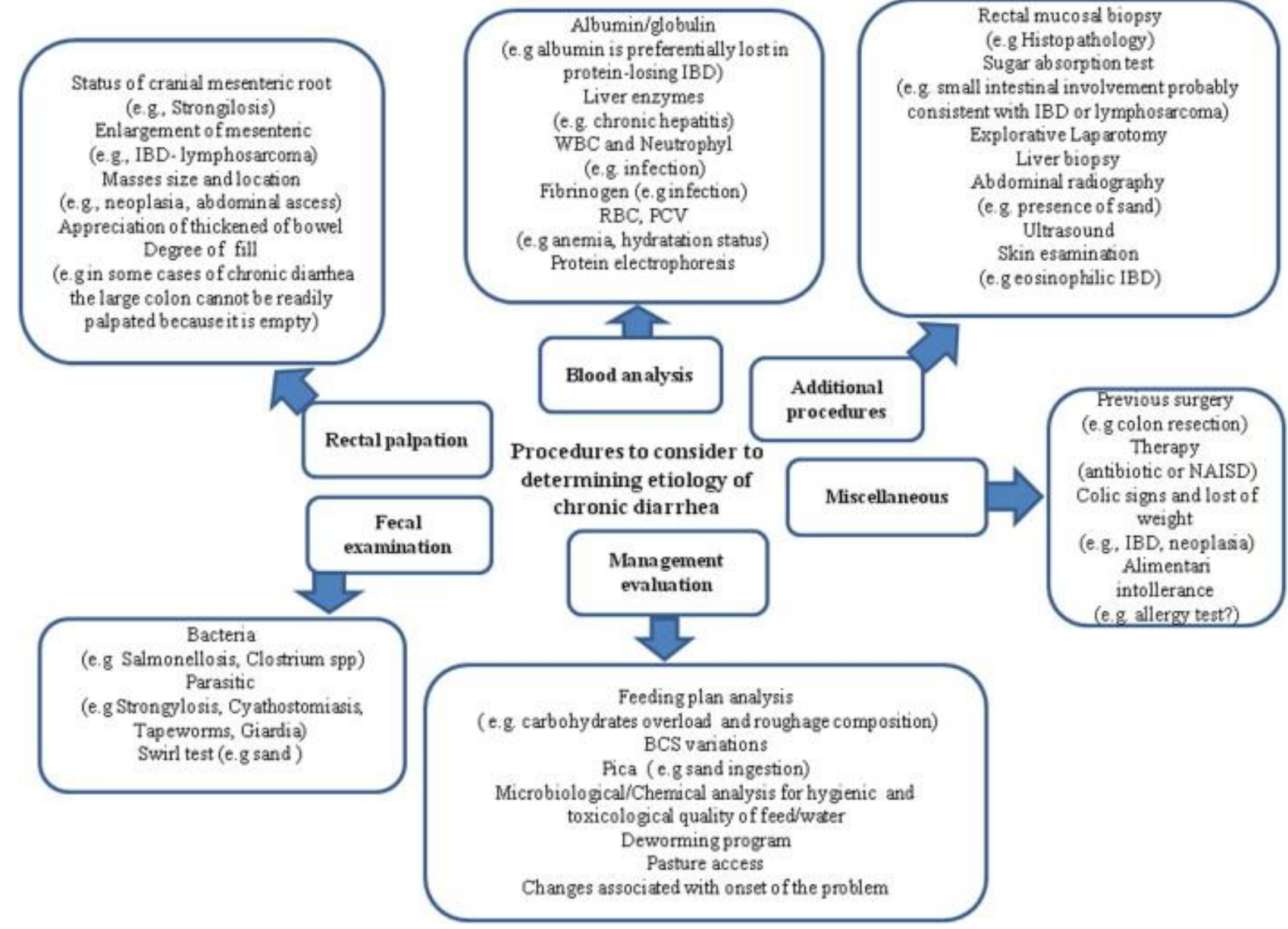

Fig. 1.

Differential diagnosis and common causes of chronic diarrhea [3], [4], [5] and [6]. 
References

[1] Gore T, Gore P, Giffin JM. Horse owner's veterinary handbook. 3th ed. Beth Adelman: Wiley Publishing Inc; 2008.

[2] Zehnder C, Pfister K, Gerhards H, Harris P, Sauter-Louis C, Kienzle E. Germany Field study on risk factors for free fecal water in pleasure horses. In Proceedings $12^{\text {th }}$ Congress of the European Society of Veterinary and Comparative Nutrition, Vienna, 25-27 September, $130 \mathrm{p}$

[3] Mair TS. Chronic diarrhea. In: Mair T, Divers T, Ducharme N, editors. Manual of equine gastroenterology, London, New York: Saunders; 2002, p 427-446.

[4] Sanchez LC. Disorder of the gastrointestinal system. In Reed SM, Bayly WM, Sellon DC, editors. Equine internal medicine 3th ed., St. Luis: Saunders; 2010; p 850-856

[5] Moreau P. Le diarree croniche nel cavallo adulto e nel puledro. Vet Prat eq 2011;13:5-19.

[6] Jones SL. Inflammatory disease of the gastrointestinal tract causing diarrhea. In Reed SM, Bayly WM, Sellon DC, editors. Equine internal medicine 3th ed., St. Luis: Saunders; 2010; p 857876.

[7] Knoll U, Strauhs P, Schusser G, Ungemach FR Study of the plasma pharmacokinetics and faecal excretion of the prodrug olsalazine and its metabolites after oral administration to horses. J Vet Pharmacol Ther. 2002; 25:135-43.

[8] The merck veterinary manual. 9 th ed. Whitehouse Station: Merck \& Co Inc; 2005.

[9] Martin-Rosset W. L'alimentation des chevaux. Paris: Institut National de la Recherche Agronomique (INRA); 1990.

[10] Malewska K, Rychlik A, Nieradka R, Kander M. Treatment of inflammatory bowel disease (IBD) in dogs and cats. Pol J Vet Sci 2011;14:165-71.

[11] Naylor J, Dunkel B. The treatment of diarrhea in the adult horse. Equine vet. Educ 2009;21:494-04.

[12] de Fombelle, Varloud M ,. Goachet AG, Jacotot E, Philippeau C, Drogoul C, et al. Characterization of the microbial and biochemical profile of the different segments of the digestive tract in horses given two distinct diets. Anim Sci 2003; 77:293-04.

[13] Kronfeld DS, Harris PA. Equine grain-associated disorders (EGA). Compend Contin Educ Pract Vet 2003; 25: 974-83.

[14] Zeyner A, Geißler C, Dittrich A. Effects of hay intake and feeding sequence on variables in faeces and faecal water (dry matter, pH value, organic acids, ammonia, buffering capacity) of horses. J Anim Physiol Anim Nutr 2004; 88:7-19. 
[15] Peiretti PG, Miraglia N, Meineri G, Costantini M, Bergero D. Apparent digestibility of barley crushed and flaked in horse diets. Ippologia 2009; 20: 17-21.

[16] Minder HP, Merritt AM, Chalupa W. In vitro fermentation of feces from normal and chronically diarrheal horses. Am J Vet Res 1980; 41:564-7.

[17] Frape D. Equine nutrition and feeding. $3^{\text {th }}$ ed. Oxford: Blackwell Publishing Ltd; 2004.

[18] Gassull MA. Review article: the intestinal lumen as a therapeutic target in inflammatory bowel disease. Aliment pharmacol Ther 2006;24:90-5.

[19] Valentine BA, Van Saun RJ, Thompson KN, Hintz HF. Role of dietary carbohydrate and fat in horses with equine polysaccharide storage myopathy. J Am Vet Med Assoc 2001;219:1537-44.

[20] de Souza A, Sandrin CZ, Moraes MG, Figuieiredo-Ribeiro RCL. Diurnal variations of nonstructural carbohydrates in vegetative tissues of Melinis minutiflora, Echinolaena inflexa and Lolium multiflorum (Poaceae). Rev bras Bot 2005; 28: 755-63

[21] Crawford C, Sepulveda MF, Elliott J, Harris PA, Bailey SR. Dietary fructan carbohydrate increases amine production in the equine large intestine: implications for pasture-associated laminitis. J Anim Sci. 2007; 85:2949-58.

[22] Galvin N, Dillon H, McG overn F. Right dorsal colitis in the horse: minireview and reports on three cases in Ireland. Irish Vet J 2004; 57: 467:73.

[23] Van Weyenberg S, Sales J, Janssens GPJ. Passage rate of digesta through the equine gastrointestinal tract: A review. Livest Sci 2006; 99:3-12.

[24] Drogoul C, Poncetb C, J Tisserand JL. Feeding ground and pelleted hay rather than chopped hay to ponies 1 . Consequences for in vivo digestibility and rate of passage of digesta. Anim Feed Sci Tech 2000; 87:117-30.

[25] Durham AE. Conditions affecting gastrointestinal tract health. In: AD, Longland AC, Coenen M, Miraglia N editors. The impact of nutrition on the health and welfare of horses, EAAP publication No 128; 2010, p 145-60.

[26] King SS, Abughazaleh AA, Webel SK, Jones KL. Circulating fatty acid profiles in response to three levels of dietary omega-3 fatty acid supplementation in horses. J Anim Sci 2008; 86:1114-23. 